\title{
Room Temperature Isothermal Colorimetric Padlock Probe Rolling Circle Amplification for Viral RNA Detection
}

\section{Authors}

Wilson Huang, Hannah Hsu, Jimmy Su, Jude Clapper, Jonathan Hsu

\begin{abstract}
Seasonal flu and pandemics, which account for millions of infections and hundreds of thousands of deaths, require rapid and reliable detection mechanisms for preventive and therapeutic measures. Current methods of viral detection have limitations in speed, accuracy, accessibility, and usability. This project presents a novel, widely applicable viral diagnosis that uses a modified version of the traditional rolling circle amplification (RCA) to be sensitive, specific, direct, colorimetric, and operable at room temperature. We are specifically aiming to detect SARS-CoV-2, Influenza A (H1N1pdm09), and Influenza B (Victoria Lineage). Results using synthetic viral DNA sequences show that the diagnostic test could take as fast as 30 minutes and detect up to picomolar concentrations of DNA strands. The next step for this project is to test the assay with synthetic viral RNA to verify the results. We envision that the implementation of this type of diagnostic test could allow faster responses to outbreaks of related viruses and quicker societal recovery.
\end{abstract}

\section{Introduction}

\section{Current Methods of Viral Detection}

Virus detection tests are imperative in the control of virus dissemination for seasonal flus and pandemics. Current methods of virus detection include blood serology, viral cultures, lateral flow immunoassays, and reverse transcriptase polymerase chain reactions (RT-PCR) (Lippi et al., 2020). However, each of these detection diagnostics has its shortcomings. Blood serology, conducted through indirect enzyme linked immunosorbent assays (ELISA), has a high incidence of cross contamination between wells, and thus can return false positives (Lippi et al., 2020). Additionally, since blood serology tests measure the antibody response in patients, this method can lead to delayed diagnosis, as an antibody response typically takes approximately 2 weeks to develop (Lippi et al., 2020). An alternative is the viral cell culture, but the growth of actual viruses could pose dangerous conditions to individuals operating the test (2019). The process of 
culturing viruses also varies in time, and therefore it can take up to 30 days before a result is obtained (CDC., 2019). Though lateral flow immunoassay is relatively quicker, it has a high rate of false negatives due to low sensitivity. This is mainly due to the failure of viral protein amplification during the detection process (CDC., 2019). Finally, RT-PCR, the gold standard in viral testing, requires expensive thermal cyclers and skilled technicians to run tests and interpret the data (Alhassan et al., 2015). RT-PCR also has limited specificity due to the reliance on reverse transcriptase for indirect cDNA targeting (Alhassan et al., 2015). Compared to other methods of detection, RT-PCR is relatively accurate. However, it is important to mention that its lowest error rate is $21 \%$ after the first 8 days after virus exposure and can go as high as $67 \%$ within the first 5 days after virus exposure (Hayek, 2020).

\section{Isothermal Nucleic Acid Amplification}

A leading and more promising approach to detection is isothermal nucleic acid amplification, which allows an assay to be run at one constant temperature. The main methods include loop mediated isothermal amplification (LAMP) and rolling circle amplification (RCA). LAMP was not chosen for this project as it requires a high temperature of $65{ }^{\circ} \mathrm{C}$ for isothermal amplification (Ge et al., 2017). LAMP also relies on reverse transcriptase for RNA virus detection, which limits the specificity of the assay due to the low fidelity of reverse transcriptase. Specifically, reverse transcriptase can make as high as 1 error per 70 polymerized nucleotides (Roberts et al., 1988).

Thus, RCA was selected as the basis of the viral diagnostic test for this project. RCA uses padlock probes that hybridize to specific complementary sequences that are targeted. The selected ligase of choice circularizes the padlock probes by ligating the 5 ' phosphate group to the 3' end of the probe (Hamidi and Ghourchian, 2015). The circular probe then serves as a template for the chosen DNA polymerase to continually synthesize DNA strands and thereby amplifying the signal (Hamidi and Perreault, 2019). If there is no complementary sequence to be targeted, this process would not occur (Gu et al., 2018). Not only is this highly sensitive and specific, but the ability to modify the procedures of RCA to conduct direct RNA testing, room temperature reactions, and colorimetric visual detection makes RCA the preeminent method for viral detection. In this study, we took advantage of the fact that dNTP usage in the synthesis of DNA strands yields hydrogen ions. By removing the buffer components in the solutions used in the reaction, using a $\mathrm{pH}$ indicator could provide a colorimetric readout to the test. We selected phi29 DNA polymerase as the DNA polymerase instead of the various Bst DNA polymerase options due to its optimal enzymatic activity at $30^{\circ} \mathrm{C}$ which is close to room temperature (de Vega et al., 2010). We used T4 DNA ligase for initial DNA target testing and SplintR ligase for RNA target testing which operates with optimal enzymatic activity at $16^{\circ} \mathrm{C}$ and $25^{\circ} \mathrm{C}$ respectively (Lohman et al., 2014; Sexton et al., 2012; Thuronyi et al., 2019). These are both near room temperature. In addition, SplintR ligase has a high fidelity, which serves the purpose of ensuring that both sides 
of the ligation junction are both complementary before catalyzing the ligation reaction (Lohman et al., 2014).

\section{Methods}

\section{Synthetic Viral Targets, Probes and Primers}

Both DNA and RNA targets were designed with BioEdit through SARS-CoV-2, Influenza A (H1N1pdm09), and Influenza B (Victoria Lineage) sequences provided in NCBI GenBank. Specifically, the Spike (S) glycoprotein gene for SARS-CoV-2 and the Hemagglutinin (HA) gene for Influenza A and B were targeted due to their high copy number in viruses. The 36 nucleotides in the specified genes of each virus were selected as targets because of their differing sequence from the same segment of other viruses. They were also selected due to the gene segment's lack of mutations across multiple cases, locations, and years.

Padlock probes were designed by adding half of the reverse complement of the target sequence to each side of the padlock probe backbone. A standard padlock probe backbone sequence that has shown to work successfully in RCA tests was chosen from literature. Since the padlock probes have to be capable of being ligated, the phosphate group modification was added to the 5' end of each probe. A forward primer complementary to the padlock probe backbone and a reverse primer that has the same sequence as another portion of the padlock probe backbone were designed. Both the forward and reverse overlap primers have two phosphorothioate modifications at the 3' end to prevent the exonuclease activity of phi29 from cutting the two primers. The reverse overlap primer synthesizes DNA strands using the complementary DNA strands synthesized from the forward primer as a template. The designed synthetic viral targets, probes, and primers were all synthesized by Integrated DNA Technologies.

\section{Buffer-free reaction solutions}

Due to this diagnostic test's dependence on $\mathrm{pH}$ change, we created ligation and amplification reaction solutions with no Tris- $\mathrm{HCl}$ buffer. These reaction solutions included the same reagents as the commercial reaction buffer from NEB but without Tris-HCl. Each $2 \mathrm{X}$ "no-Tris" ligation solution with $20 \mathrm{mM}$ of $\mathrm{MgCl}_{2}, 2 \mathrm{mM}$ of ATP, $20 \mathrm{mM}$ of DTT, $3.5 \mathrm{mM}$ of $\mathrm{NaOH}$ was made in a $100 \mu \mathrm{L}$ stock. Similarly, each $2 \mathrm{X}$ "no-Tris" amplification solution with 20 $\mathrm{mM}$ of $\mathrm{MgCl}_{2}, 20 \mathrm{mM}$ of $\left(\mathrm{NH}_{4}\right)_{2} \mathrm{SO}_{4}, 8 \mathrm{mM}$ of DTT, $2.8 \mathrm{mM}$ of dNTP, $2 \mathrm{mM}$ of NaOH was made in a $100 \mu \mathrm{L}$ stock.

\section{Ligation and amplification reactions}

The ligation and rolling circle amplification (RCA) reactions were run simultaneously in the same PCR tube at a total volume of $40 \mu \mathrm{L}$. For the ligation reaction, $5 \mu \mathrm{L}$ of $2 \mathrm{X}$ "no-Tris" ligation solution was added to $1 \mu \mathrm{L}$ of a $2.5 \mu \mathrm{M}$ DNA Target, $1 \mu \mathrm{L}$ of a $10 \mu \mathrm{M}$ padlock probe (PLP), $1 \mu \mathrm{L}$ of T4 ligase, and $2 \mu \mathrm{L}$ of deionized $\mathrm{H}_{2} \mathrm{O}$. For the amplification reaction, $20 \mu \mathrm{L}$ of $2 \mathrm{X}$ 
"no-Tris" amplification solution, $2 \mu \mathrm{L}$ of $24 \mu \mathrm{M}$ forward primer (PLP-1), $2 \mu \mathrm{L}$ of $24 \mu \mathrm{M}$ reverse overlap primer (PLP-2), $5 \mu \mathrm{L}$ of $0.05 \%$ Phenol Red, and $1 \mu \mathrm{L}$ of phi2 9 were added to the $10 \mu \mathrm{L}$ ligation mixture. Let the PCR tube sit at room temperature for 1 hour.

\section{Optimization, Sensitivity, and Time Course Tests}

Since each reaction contained a multitude of variables that might affect the overall time for a color change to occur, many different concentrations and amounts of each component were tested to reach the optimal setting. Specifically, the $10 \mathrm{U}, 20 \mathrm{U}$, and $30 \mathrm{U}$ of phi29, $0.1 \mu \mathrm{M}$, $0.25 \mu \mathrm{M}, 0.5 \mu \mathrm{M}$, and $1 \mu \mathrm{M}$ of PLP, $2.0 \mu \mathrm{L}, 3.0 \mu \mathrm{L}$, and $3.5 \mu \mathrm{L}$ of $\mathrm{NaOH}$ in the amplification reaction solution, and $0.05 \%$ and $0.005 \%$ of phenol red were tested independently. The optimal concentration and amount for each substance determined through testing of these various variables were as described above.

For the sensitivity, the 2.5uM DNA Target used was diluted to $2.5 \mathrm{nM}$ and $2.5 \mathrm{pM}$ DNA target samples. The same reaction was run with these lower concentrations of DNA targets to see the extent to which the test can diagnose the low amounts of a virus. $2 \mu \mathrm{L}$ of phi29 was used to maximize the effectiveness of the test.

The purpose of the time course tests were to obtain qualitative evidence that the color change in the assay was due to DNA amplification. In order to do so, we ran the ligation and amplification reaction, but took aliquots of $10 \mu \mathrm{L}$ out after every 10 minutes from the initial $40 \mu \mathrm{L}$, and heat shocked these aliquots at $60^{\circ} \mathrm{C}$ for 10 minutes as the heat would have inactivated the reaction, and repeated until the initial tube only had $10 \mu \mathrm{L}$ remaining. We then ran a $1 \%$ DNA gel to confirm the presence of DNA.

\section{Modeling Data Collection and Analysis}

Reactions containing different concentrations of a DNA target and its corresponding PLP were carried out in distinct PCR tubes to evaluate the effect of each component on the reaction rate (Table \#3). These reactions were run at $20 \mu \mathrm{L}$ with the concentration of each component except for the DNA target and its complementary PLP kept the same. A negative control consisting of non-matching DNA target and PLP pairs was run and recorded simultaneously. All reactions were recorded together in a time-lapse video.

The volume of the reactions was insufficient for standard methods of spectrophotometry, and thus computer vision was used to quantify the reactions. Pixels displaying the reactions were isolated in each frame of the time-lapse video, and values outside an empirically determined number of standard deviations from the mean were removed as outliers. The remaining pixels in each frame were averaged to plot mean hue against time. (Figure \#1). 


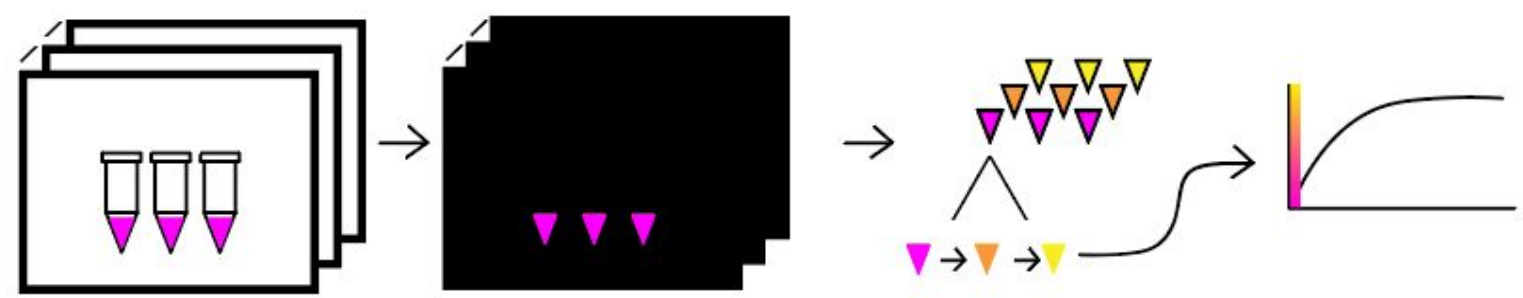

Figure \#1. Masks are created by drawing polygons around the pixels representing the reaction. The masks are then applied to each frame, and the values of the isolated pixels are obtained and plotted against time.

\section{Results and Discussion}

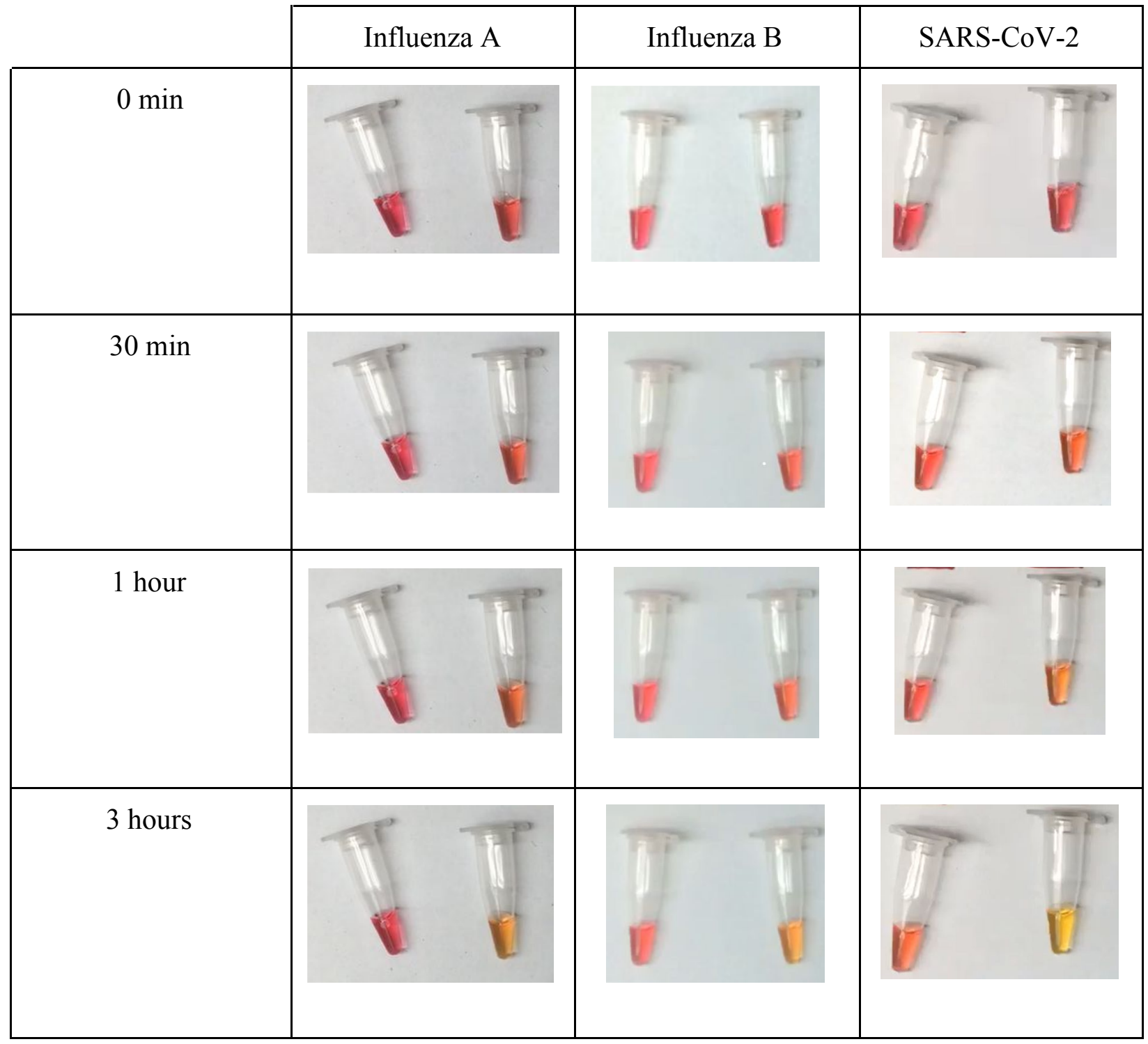

Table \#1. Influenza A, Influenza B, and SARS-CoV-2 Padlock Probe Test. The negative control is shown on the left side and the test group is shown on the right side of the two tubes. 
Based on Table \#1, the results show that a visual color change for the reaction can occur as fast as 30 minutes with the test groups turning orange and the negative remaining purple for influenza A, influenza B, and SARS-CoV-2 tests. By 3 hours, the test group changes to yellow and the negative control still remains purple. But in some instances such as the SARS-CoV-2 test, the negative control changed slightly orange. However, the test groups still arrived at a color change to both orange and yellow at a much faster speed than the negative control managed to reach an orange color. This enables the presence of the virus being tested to be identified accurately with a predetermined time to examine the results of the diagnostic test.

\begin{tabular}{|c|c|c|c|}
\hline $0 \mathrm{~min}$ & 1 hour & 3 hours & 5 hours \\
\hline$\frac{1}{7} \frac{2}{7} \frac{3}{7}$ & $\frac{1}{7} \quad \frac{3}{7}$ & $\frac{1}{P}=\frac{3}{F}$ & $\frac{1}{7} \frac{2}{7} \frac{3}{7}$ \\
\hline 8 \& 8 & 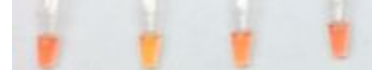 & 8000 & 60 \\
\hline
\end{tabular}

Table \#2. Sensitivity Test for SARS-CoV-2. Tube \#1 is the negative control with $2.5 \mathrm{uM}$ of influenza A target. Tube \#2 is a test group with $2.5 \mathrm{uM}$ of SARS-CoV-2 target. Tube \#3 is a test group with $2.5 \mathrm{nM}$ of SARS-CoV-2 target. Tube \#4 is a test group with $2.5 \mathrm{pM}$ of SARS-CoV-2 target.

The sensitivity test results as shown in Table \#2, shows that this diagnostic test has the capability to detect not just micromolar concentrations of synthetic viral targets, but also up to picomolar concentrations. It is important to mention that the test appears to have started at an orange color for all tubes due to the strong lighting at the time of recording as well as the rapid color change from purple to orange that occured for the tests.

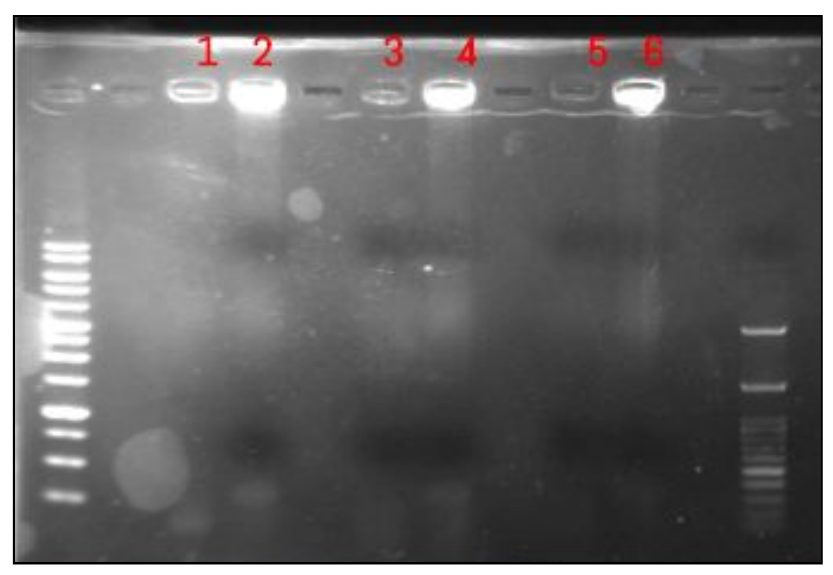

Figure \#2. A time course test for Influenza B was run on 1\% agarose gel and imaged using a UV scanner. Negative Controls were treated with a SARS-CoV-2 target, test groups were treated with an Influenza B target, and all tests used an Influenza B padlock probe. The leftmost lane was a $1 \mathrm{~kb}$ DNA ladder; lane 1 was the negative control after 20 minutes; lane 2 was the test group after 20 minutes; lane 3 was the negative control after 30 minutes; lane 4 was the test group after 30 minutes; lane 5 was the negative control after 40 minutes; lane 6 is the test group after 40 minutes; and the rightmost lane was a 100bp DNA ladder. 
The time course test shown in Figure \#2 suggests that DNA amplification is in fact taking place due to the smears of DNA across the gel in the test group. In addition, the bright lights visualized in the wells of the test group compared to the negative control may further suggest that tangled and clumps of DNA strands synthesized is at such a high quantity that it is unable to pass through the porous of the gel. We also attempted to use less concentrated gels but the later of gel integrity simply made it difficult to even allow it to stay intact.

\begin{tabular}{|c|c|c|c|c|c|c|c|}
\hline \multirow{8}{*}{$\begin{array}{l}\text { DNA Target } \\
\text { Concentration } \\
(\mu \mathrm{M})\end{array}$} & \multicolumn{7}{|c|}{ PLP Concentration $(\mu \mathrm{M})$} \\
\hline & & & A & B & $\mathrm{C}$ & $\mathrm{D}$ & $\mathrm{E}$ \\
\hline & & & $0.0625 \mu \mathrm{M}$ & $0.09375 \mu \mathrm{M}$ & $0.125 \mu \mathrm{M}$ & $0.15625 \mu \mathrm{M}$ & $0.1875 \mu \mathrm{M}$ \\
\hline & 1 & $0.0625 \mu \mathrm{M}$ & A1 & $\mathrm{B} 1$ & $\mathrm{C} 1$ & & E1 \\
\hline & 2 & $0.09375 \mu \mathrm{M}$ & $\mathrm{A} 2$ & B2 & & D2 & \\
\hline & 3 & $0.125 \mu \mathrm{M}$ & A3 & & $\mathrm{C} 3$ & & \\
\hline & 4 & $0.15625 \mu \mathrm{M}$ & & B4 & & & \\
\hline & 5 & $0.1875 \mu \mathrm{M}$ & A5 & & & & \\
\hline
\end{tabular}

Table \#3. Each cell represents the combination of DNA Target and PLP concentrations in a reaction. Magenta cells indicate combinations that were not tested due to volume restrictions. The reactions were run at a volume of $20 \mu \mathrm{L}$ and the concentrations were determined by volume. 
bioRxiv preprint doi: https://doi.org/10.1101/2020.06.12.128876; this version posted July 15, 2020. The copyright holder for this preprint (which was not certified by peer review) is the author/funder, who has granted bioRxiv a license to display the preprint in perpetuity. It is made available under aCC-BY-NC-ND 4.0 International license.

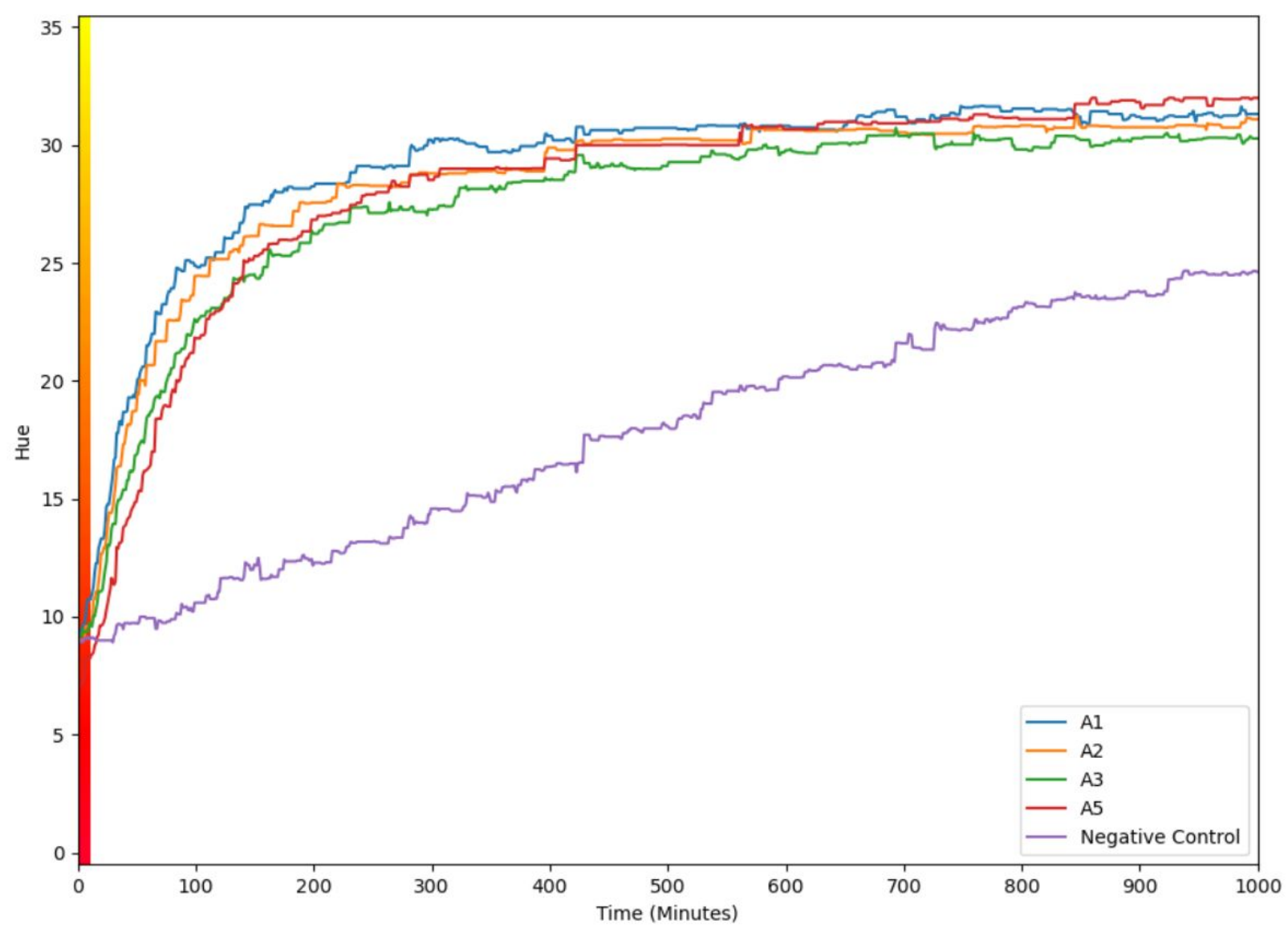

Figure \#3. The change of hue over time of reactions A1, A2, A3, A5, and a negative control. 
bioRxiv preprint doi: https://doi.org/10.1101/2020.06.12.128876; this version posted July 15, 2020. The copyright holder for this preprint (which was not certified by peer review) is the author/funder, who has granted bioRxiv a license to display the preprint in perpetuity. It is made available under aCC-BY-NC-ND 4.0 International license.

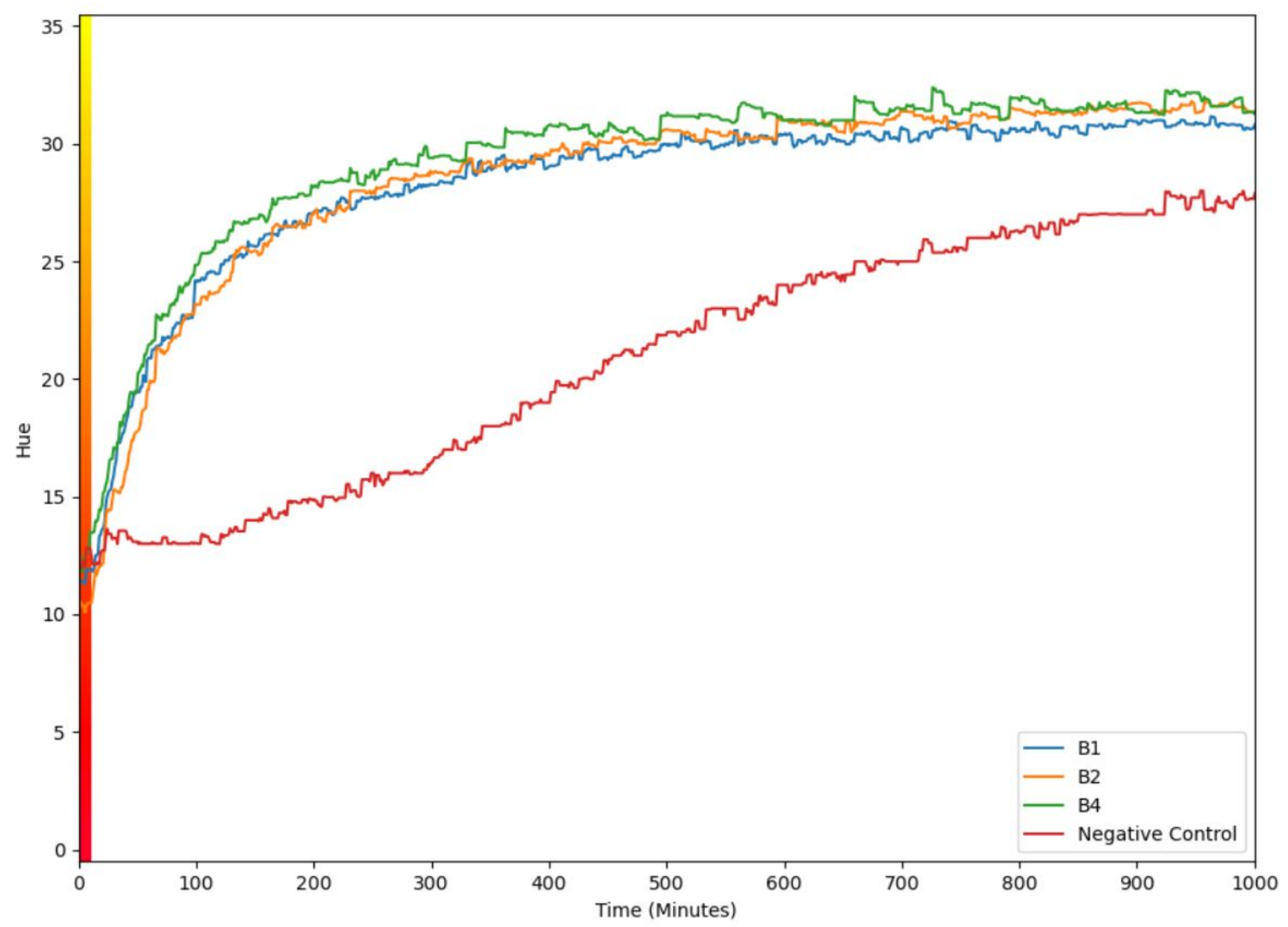

Figure \#4. The change of hue over time of reactions B1, B2, B4, and a negative control. 


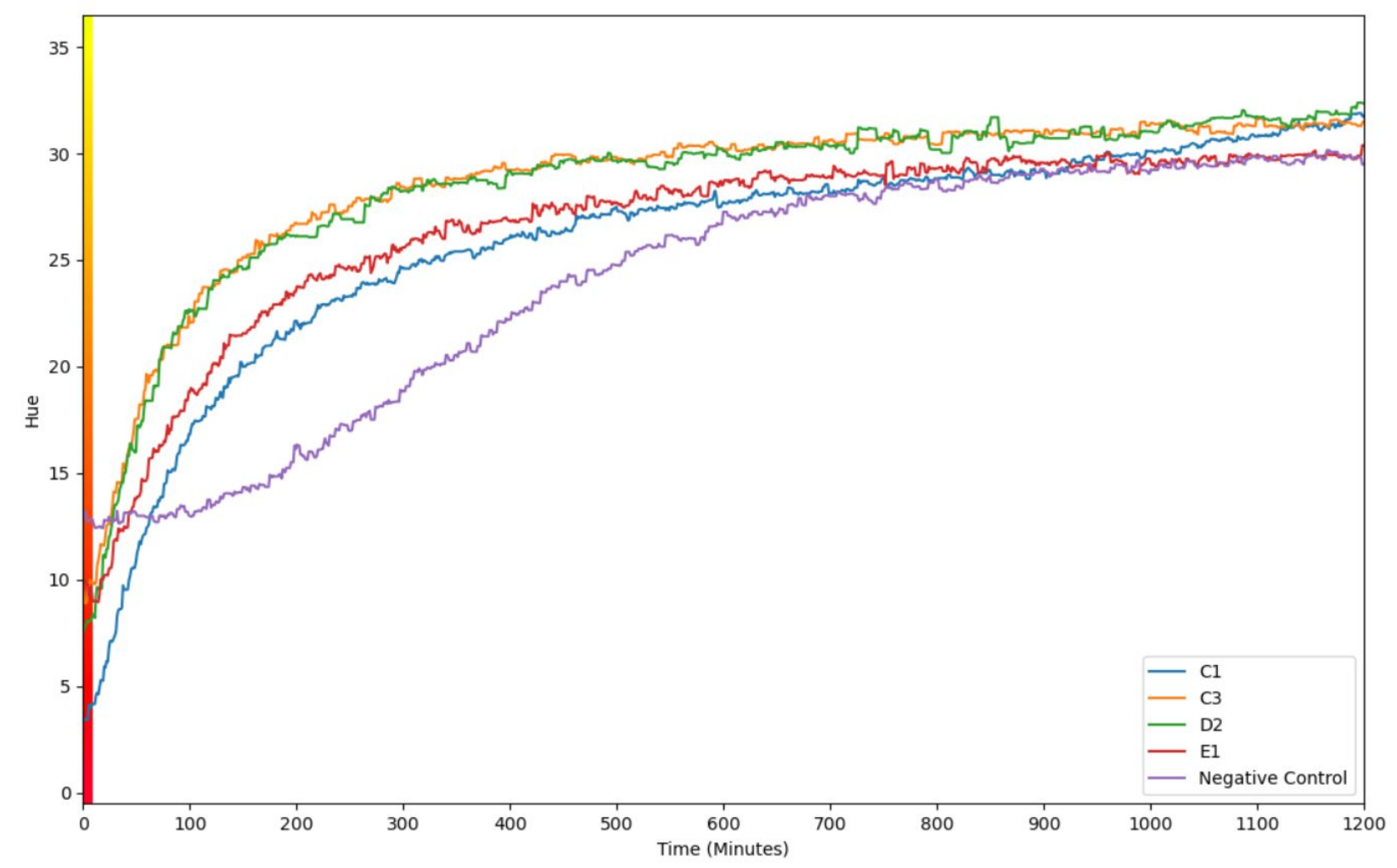

Figure \#5. The change of hue over time of reactions C1, C3, D2, E1, and a negative control.

According to Figure 3, the rates of the reactions - determined by the speed of hue change - are fast during the first hour, and then gradually plateaus after 2 hours. Not only does this corroborate with previous conclusions based on visual analysis, but the trend exhibited by the reactions in Figure 3 is also shared among the other reactions as shown in Figures 3, and 3. Although the negative control ultimately reaches a yellowish hue, it changes color at an extremely slow and seemingly constant rate (Figure 3 ).

We suspect that the slight change in color for the negative control occurs due to the function of T4 ligase. Unlike enzymes such as HiFi Taq DNA ligase, T4 ligase does not check whether each side of the ligation junction is fully complementary before catalyzing the ligation reaction. For this reason, we believe that it is possible that partial complementary sequences between the mismatched target and padlock probe sequence could've caused ligation and circularization of the probe. Though this does not impede this diagnostic test's ability to differentiate between two viruses, we also believe that this issue will be solved in the plans discussed under further directions.

Computer vision was chosen to analyze the reactions' rates over traditional methods like the use of a $\mathrm{pH}$ meter or plate reader due to several reasons. One reason was that the miniscule volume of the reactions was insufficient for proper spectrophotometry and required a specialized, expensive $\mathrm{pH}$ probe for the measurement of $\mathrm{pH}$. By using computer vision, this obstacle was 
overcome, as most measurements could now be done on more accessible machines. Steps required for computer vision are also more straightforward than those for the traditional methods, and thus the amount of work to perform data analysis is greatly reduced. Through the use of computer vision, a more accurate analysis could also be made, as its use allowed the recording of many more data points in a certain timeframe. However, the use of computer vision potentially yields sources of error, as it can be sensitive to environmental factors such as changes in light intensity. Due to uncontrollable factors, the light may alter slightly between windows and can vary across different recordings. The effect of this source of error is minimized by keeping the light source, camera, and PCR tubes' positions consistent and running multiple reactions simultaneously. Additionally, hue, as a measurement of perceived light, is theoretically unaffected by brightness and saturation.

\section{Further Directions}

Although this current viral diagnostic test uses DNA targets, we plan to use the designed RNA targets to verify the results. In order for ligation to function for a RNA and DNA padlock probe hybrid to occur, SplintR ligase will be used. SplintR ligase is used for SNP level detection for ligating only fully complementary RNA and DNA hybrid segments. This could potentially prevent possible ligations of padlock probes through non-complementary binding between the target and padlock probe, and eliminate the slight color change that occurs in the negative control after numerous hours.

We aim to use this simple viral diagnostic test to create a test kit that can be used by not only hospital staff and laboratory technicians, but by consumers at home as well. To do so, we will also develop a simple and quick sample preparation technique for viral extracts from the patients and possible better alternatives to a nasopharyngeal swab.

Though micro-pH probes are available for the measurement of $\mathrm{pH}$ at extremely small volumes, micro-pH probes are typically very expensive. Thus, we are also working to use computer vision techniques to approximate the $\mathrm{pH}$ of the reactions. Using a set of standard solutions as shown in Figure \#6, we have already created a regression curve relating hue to $\mathrm{pH}$. The goal is to approximate $\mathrm{pH}$ by fitting hue obtained from experiments to the curve (Figure \#7). We also plan on eliminating possible confounding variables such as light reflection in order to reliably approximate the $\mathrm{pH}$ of the reactions. 


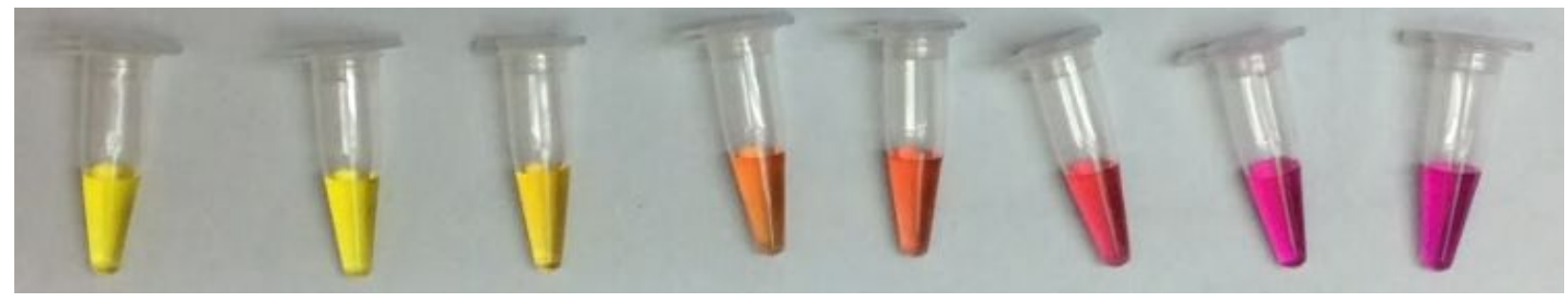

Figure \#6. pH standards from left to right: 4.0, 5.0, 6.0, 7.0, 7.42, 8.0, 9.0, 10.0 showing the color change of phenol red across set pHs.

Figure \#7. Regression curve obtained from analyzing solutions with known $\mathrm{pH}$. Hue refers to 'Hue' in the Hue, Saturation, and Value color scale. The 'hue' scale was slightly offset to cover the range of colors expressed throughout the reaction.

\section{References}

Alhassan, Andy, Zhiru Li, Catherine B. Poole, and Clotilde K.S. Carlow. "Expanding the MDx Toolbox for Filarial Diagnosis and Surveillance." Trends in Parasitology 31, no. 8 (August 2015): 391-400. https://doi.org/10.1016/j.pt.2015.04.006. American College of Cardiology. "False-Negative Rate of RT-PCR SARS-CoV-2 Tests." Accessed June 5, 2020.

http $\% 3 \mathrm{a} \% 2 \mathrm{f} \% 2 \mathrm{fwww}$.acc.org $\% 2$ flatest-in-cardiology $\% 2$ fjournal-scans $\% 2 \mathrm{f} 2020 \% 2 \mathrm{f0}$ Corman, Victor M, Olfert Landt, Marco Kaiser, Richard Molenkamp, Adam Meijer, Daniel 
KW Chu, Tobias Bleicker, et al. "Detection of 2019 Novel Coronavirus (2019-NCoV)

by Real-Time RT-PCR.” Eurosurveillance 25, no. 3 (January 23, 2020).

https://doi.org/10.2807/1560-7917.ES.2020.25.3.2000045.

Deng, Ruijie, Kaixiang Zhang, Yupeng Sun, Xiaojun Ren, and Jinghong Li. "Highly

Specific Imaging of MRNA in Single Cells by Target RNA-Initiated Rolling Circle

Amplification." Chemical Science 8, no. 5 (2017): 3668-75.

https://doi.org/10.1039/C7SC00292K.

Drosten, Christian, Stephan Günther, Wolfgang Preiser, Sylvie van der Werf,

Hans-Reinhard Brodt, Stephan Becker, Holger Rabenau, et al. "Identification of a

Novel Coronavirus in Patients with Severe Acute Respiratory Syndrome." New

England Journal of Medicine 348, no. 20 (May 15, 2003): 1967-76.

https://doi.org/10.1056/NEJMoa030747.

Dziąbowska, Karolina, Elżbieta Czaczyk, and Dawid Nidzworski. "Detection Methods of

Human and Animal Influenza Virus - Current Trends.” Biosensors 8, no. 4 (October

18, 2018): 94. https://doi.org/10.3390/bios8040094.

Fink, C. G. "Molecular Methods for Virus Detection.” Molecular Pathology 50, no. 2 (April

1, 1997): 111-111. https://doi.org/10.1136/mp.50.2.111-a.

Franzén, Mikael. “Covid-19 Rapid Test - BLUE PAPER.” Preprint. Open Science

Framework, March 10, 2020. https://doi.org/10.31219/osf.io/jpukc.

Ge, Yiyue, Bin Wu, Xian Qi, Kangchen Zhao, Xiling Guo, Yefei Zhu, Yuhua Qi, et al.

"Rapid and Sensitive Detection of Novel Avian-Origin Influenza A (H7N9) Virus by

Reverse Transcription Loop-Mediated Isothermal Amplification Combined with a

Lateral-Flow Device.” Edited by Xue-jie Yu. PLoS ONE 8, no. 8 (August 1, 2013):

e69941. https://doi.org/10.1371/journal.pone.0069941.

Ge, Yiyue, Qiang Zhou, Kangchen Zhao, Ying Chi, Bin Liu, Xiaoyan Min, Zhiyang Shi,

Bingjie Zou, and Lunbiao Cui. "Detection of Influenza Viruses by Coupling Multiplex

Reverse-Transcription Loop-Mediated Isothermal Amplification with Cascade Invasive

Reaction Using Nanoparticles as a Sensor.” International Journal of Nanomedicine

Volume 12 (April 2017): 2645-56. https://doi.org/10.2147/IJN.S132670.

Gu, Lide, Wanli Yan, Le Liu, Shujun Wang, Xu Zhang, and Mingsheng Lyu. "Research

Progress on Rolling Circle Amplification (RCA)-Based Biomedical Sensing."

Pharmaceuticals 11, no. 2 (April 21, 2018): 35. https://doi.org/10.3390/ph11020035.

Gyarmati, P., T. Conze, S. Zohari, N. LeBlanc, M. Nilsson, U. Landegren, J. Baner, and S. 
Belak. "Simultaneous Genotyping of All Hemagglutinin and Neuraminidase Subtypes of Avian Influenza Viruses by Use of Padlock Probes." Journal of Clinical

Microbiology 46, no. 5 (May 1, 2008): 1747-51.

https://doi.org/10.1128/JCM.02292-07.

Hamidi, Seyed Vahid, and Hedayatollah Ghourchian. "Colorimetric Monitoring of Rolling Circle Amplification for Detection of H5N1 Influenza Virus Using Metal Indicator." Biosensors and Bioelectronics 72 (October 2015): 121-26.

https://doi.org/10.1016/j.bios.2015.04.078.

Hamidi, Seyed Vahid, and Jonathan Perreault. "Simple Rolling Circle Amplification Colorimetric Assay Based on PH for Target DNA Detection.” Talanta 201 (August 2019): 419-25. https://doi.org/10.1016/j.talanta.2019.04.003.

Hartman, Mark R., Roanna C. H. Ruiz, Shogo Hamada, Chuanying Xu, Kenneth G. Yancey, Yan Yu, Wei Han, and Dan Luo. "Point-of-Care Nucleic Acid Detection Using Nanotechnology." Nanoscale 5, no. 21 (2013): 10141.

https://doi.org/10.1039/c3nr04015a.

Khan, Muhammad Imran, Koushik Mukherjee, Rizwan Shoukat, and Huang Dong. "A

Review on PH Sensitive Materials for Sensors and Detection Methods.” Microsystem

Technologies 23, no. 10 (October 2017): 4391-4404.

https://doi.org/10.1007/s00542-017-3495-5.

Larsson, Chatarina, Ida Grundberg, Ola Söderberg, and Mats Nilsson. "In Situ Detection and Genotyping of Individual MRNA Molecules.” Nature Methods 7, no. 5 (May 2010):

395-97. https://doi.org/10.1038/nmeth.1448.

Larsson, Chatarina, Jørn Koch, Anders Nygren, George Janssen, Anton K Raap, Ulf

Landegren, and Mats Nilsson. "In Situ Genotyping Individual DNA Molecules by

Target-Primed Rolling-Circle Amplification of Padlock Probes." Nature Methods 1, no.

3 (December 2004): 227-32. https://doi.org/10.1038/nmeth723.

Lippi, Giuseppe, Camilla Mattiuzzi, Chiara Bovo, and Mario Plebani. "Current Laboratory

Diagnostics of Coronavirus Disease 2019 (COVID-19)." Acta Bio Medica Atenei

Parmensis 91, no. 2 (May 11, 2020): 137-45. https://doi.org/10.23750/abm.v91i2.9548.

Lohman, Gregory J. S., Yinhua Zhang, Alexander M. Zhelkovsky, Eric J. Cantor, and

Thomas C. Evans. "Efficient DNA Ligation in DNA-RNA Hybrid Helices by Chlorella Virus DNA Ligase." Nucleic Acids Research 42, no. 3 (February 2014): 1831-44.

https://doi.org/10.1093/nar/gkt1032. 
“Rapid Influenza Diagnostic Tests | CDC,” November 12, 2019.

https://www.cdc.gov/flu/professionals/diagnosis/clinician guidance ridt.htm.

Roberts, J., K Bebenek, and T. Kunkel. "The Accuracy of Reverse Transcriptase from HIV-1." Science 242, no. 4882 (November 25, 1988): 1171-73.

https://doi.org/10.1126/science.2460925.

Rota, P. A. "Characterization of a Novel Coronavirus Associated with Severe Acute Respiratory Syndrome.” Science 300, no. 5624 (May 30, 2003): 1394-99.

https://doi.org/10.1126/science.1085952.

Schott, Juliane W, Michael Morgan, Melanie Galla, and Axel Schambach. "Viral and Synthetic RNA Vector Technologies and Applications." Molecular Therapy 24, no. 9 (September 2016): 1513-27. https://doi.org/10.1038/mt.2016.143.

Sexton, Tom, Sreenivasulu Kurukuti, Jennifer A Mitchell, David Umlauf, Takashi Nagano, and Peter Fraser. "Sensitive Detection of Chromatin Coassociations Using Enhanced Chromosome Conformation Capture on Chip." Nature Protocols 7, no. 7 (July 2012): 1335-50. https://doi.org/10.1038/nprot.2012.071.

Thakore, Nitu, Ryan Norville, Molly Franke, Roger Calderon, Leonid Lecca, Michael Villanueva, Megan B. Murray, Christopher G. Cooney, Darrell P. Chandler, and Rebecca C. Holmberg. "Automated TruTip Nucleic Acid Extraction and Purification from Raw Sputum.” Edited by Sylvia Bruisten. PLOS ONE 13, no. 7 (July 5, 2018): e0199869. https://doi.org/10.1371/journal.pone.0199869.

Thuronyi, Benjamin W., Luke W. Koblan, Jonathan M. Levy, Wei-Hsi Yeh, Christine Zheng, Gregory A. Newby, Christopher Wilson, et al. "Continuous Evolution of Base Editors with Expanded Target Compatibility and Improved Activity." Nature Biotechnology 37, no. 9 (September 2019): 1070-79.

https://doi.org/10.1038/s41587-019-0193-0.

Vashist, Sandeep Kumar. "In Vitro Diagnostic Assays for COVID-19: Recent Advances and Emerging Trends.” Diagnostics 10, no. 4 (April 5, 2020): 202.

https://doi.org/10.3390/diagnostics10040202.

Vega, M. de, J. M. Lazaro, M. Mencia, L. Blanco, and M. Salas. "Improvement of 29 DNA

Polymerase Amplification Performance by Fusion of DNA Binding Motifs."

Proceedings of the National Academy of Sciences 107, no. 38 (September 21, 2010):

16506-11. https://doi.org/10.1073/pnas.1011428107.

Zedalis, Julianne, John Eggebrecht, and OpenStax College. Biology for AP® Courses, 2017. 
bioRxiv preprint doi: https://doi.org/10.1101/2020.06.12.128876; this version posted July 15,2020 . The copyright holder for this preprint (which was not certified by peer review) is the author/funder, who has granted bioRxiv a license to display the preprint in perpetuity. It is made available under aCC-BY-NC-ND 4.0 International license.

\section{https://openstax.org/details/books/biology-ap-courses.}




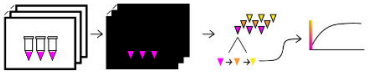

Iignee ' d. Muls are creeced by drowing polygons arwad the pixels represeutug the reaction. The mash

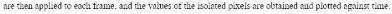




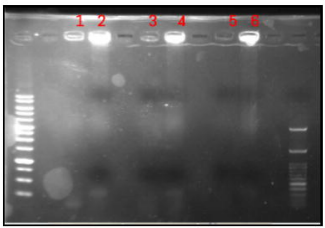

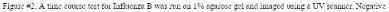

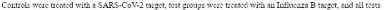

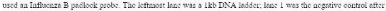

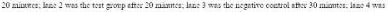

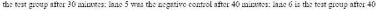

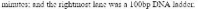




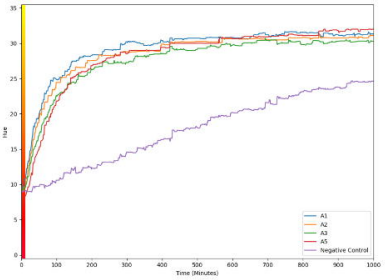

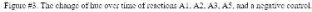




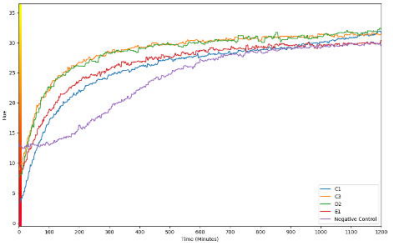

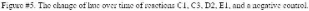



Husus $\alpha-1$

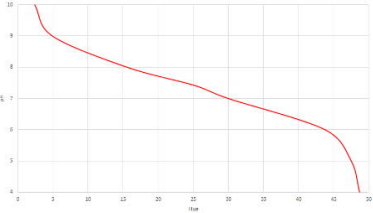

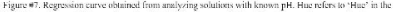

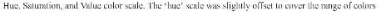
cxpresscal througtxul the restion. 


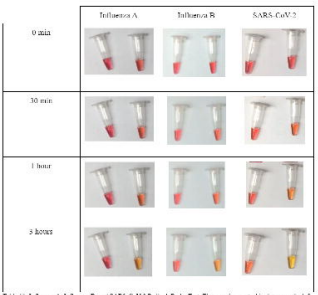

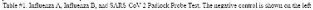

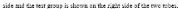




\section{$0 \mathrm{~min}$}

\section{1 hour}

\section{3 hours \\ 3 hours}

5 hours

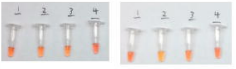

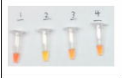

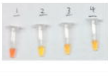

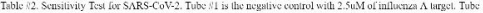
$\neq 2$ is a test grup with $2.5 \mathrm{aM}$ of $\$ \mathrm{AllS}-6 \mathrm{OV}-2$ target. Jube $\neq 3$ is a test group with $2.5 \mathrm{nM}$ of SARS-f $6 \mathrm{~V}-2$ target. Iuhe $\Rightarrow 4$ is a test group with $2.5 \mathrm{pM}$ of SARS Covi 2 target. 
PLP (odecumtion If (M)

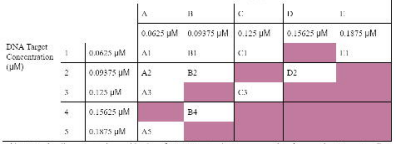

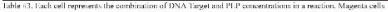

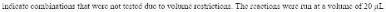

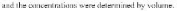

